\title{
How Billionaires Explain Their Philanthropy: A Mixed-Method Analysis of the Giving Pledge Letters
}

\author{
Hans Peter Schmitz ${ }^{1}$ (i) George E. Mitchell ${ }^{2}$ - Elena M. McCollim ${ }^{3}$
}

Accepted: 17 February 2021

(C) The Author(s) 2021

\begin{abstract}
This study investigates a discourse about billionaire philanthropy established in letters submitted by 187 of 209 signatories of the Giving Pledge. The philanthropy of the wealthy is gaining increasing public attention and is subject to growing criticism, which demands additional study of how the wealthy collectively explain their generosity. The mixed-method analysis finds a strong emphasis on education and health causes and identifies two distinct and coherent rationales for being generous. The majority of letters express a social-normative rationale, consisting of two prevailing explanations: an expressed gratitude and desire to "give back" (1) and references to family upbringing as a socializing force (2). A minority of letters articulate a personal-consequentialist rationale, highlighting three separate explanations: a large inheritance may harm offspring (1), giving as personal gratification (2), and an acknowledgment of excess wealth with no better use (3). An expressed desire to have impact and make a difference appears in both rationales. The overall dominance of a social-normative rationale projects a discourse emphasizing benevolence as well as a narrative in
\end{abstract}

Hans Peter Schmitz

schmitz@sandiego.edu

George E. Mitchell

george.mitchell@baruch.cuny.edu

Elena M. McCollim

elena.mccollim@faculty.umgc.edu

1 Department of Leadership Studies, University of San Diego, 5998 Alcalá Park, San Diego, CA, USA

2 Marxe School of Public and International Affairs, Baruch College, City University of New York, One Bernard Baruch Way, New York, NY 10010, USA

3 University of Maryland Global Campus, Adelphi, MD, USA which billionaires are an exceptionally productive and grateful subset of society. While previous studies have primarily focused on identifying individual psychological motives, this study shows how the Giving Pledge letters reflect a philanthropic discourse among the wealthy going back to Andrew Carnegie's Gospel of Wealth.

Keywords Billionaire philanthropy · Giving Pledge · Qualitative document analysis - Latent class analysis

\section{Introduction}

In 2010, Bill and Melinda Gates in collaboration with Warren Buffett announced the creation of the Giving Pledge as a tool to increase philanthropic giving among fellow billionaires. The idea of the Giving Pledge emerged after a number of private meetings organized by the Gateses shortly after the end of the 2008/2009 global financial crisis (Loomis, 2010). By March 2020, 209 individuals and couples had signed the pledge, ${ }^{1}$ promising to give at least half of their wealth away during their lifetime. The voluntary pledge aims "to help shift the social norms of philanthropy toward giving more, giving sooner, and giving smarter" (The Giving Pledge, 2019).

As wealthy donors exert significant philanthropic influence, their collective accounts of why and how they give have drawn increasing attention and criticism (Callahan, 2017; McGoey, 2016). Accelerated wealth accumulation and income inequality are changing the philanthropic landscape across the world with important implications for

\footnotetext{
${ }^{1}$ By December 2020, the total number of pledgers increased by seven to 216. The cutoff date for data collection for this study was in early March 2020.
} 
public policy. The percentage of US households giving to nonprofits dropped from 66 percent in 2000 to 55 percent in 2014 (Rooney, 2018). At the same time, total charitable giving by individuals, foundations, and corporations has increased every year (to almost $\$ 450 \mathrm{bn}$ in 2019) since the late 1970s, except for 1987, 2008, and 2009 (Giving USA Foundation, 2020). There is some evidence that the relative philanthropic influence of wealthier households is increasing in the USA and elsewhere (Collins \& Flannery, 2020). These changes in giving patterns have led scholars to call for greater attention to the philanthropic actions of the wealthy and their effects on the nonprofit sector and democracy more broadly (Reich, 2018; Saunders-Hastings, 2018; Skocpol, 2016).

This study analyzes letters by Giving Pledge members to better understand the discourse about philanthropy among the wealthy. It asks how members of the Giving Pledge explain their generosity and in what ways their collective discourse expressed in writing compares to earlier statements on wealthy giving, specifically Andrew Carnegie's Gospel of Wealth. In this endeavor, we build on two distinct bodies of literature. One is focused on elite donor culture, broadly defined, and seeks to uncover psychological motivations for giving among the wealthy (e.g., Breeze \& Lloyd, 2013; Ostrower, 1995; Schervish, 2007; Worth et al. 2019). The second set of studies focuses specifically on the Giving Pledge population (e.g., Coupe \& Monteiro, 2016; Sadeh et al. 2017) with a similar focus on extracting information about underlying motives.

We extend these studies with two specific contributions. First, this study goes beyond previous studies of the Giving Pledge by analyzing a greater number of letters, while also adding demographic data on pledgers and refining previous coding schemata (Table 3). Second, this analysis establishes two distinct and novel rationales that underlie elite philanthropists' publicly stated explanations for giving. Building on earlier studies of wealthy donors, we identify a dominant social-normative rationale alongside a less prevalent personal-consequentialist rationale. Rejecting a simplistic dualism of altruistic and egoistic motives for giving (Herzog \& Price, 2016; Worth et al. 2019), our analysis organizes a number of distinct explanations for giving into two coherent profiles (Table 6). In contrast to earlier studies of the Giving Pledge population, we consider the letters not just as vessels of data to derive individual motives, but as social products of, and contributions to elite philanthropic discourse. The dominant rationale identified across the letters projects an image of benevolent gratitude whereby generosity is an appropriate way of managing excess wealth.

The next section summarizes existing studies on the philanthropy of the wealthy as well as the Giving Pledge. This provides the context for the analysis presented in this study. The subsequent section offers background information on the Giving Pledge and a summary of demographic information about its signatories. This is followed by a description of the analytical procedure employed for this study. The subsequent section on empirical findings is divided into two parts describing first the dominant philanthropic causes identified in the letters and then analyzing the explanations for philanthropic generosity as stated by the signatories. The conclusions section then relates the results to the existing literature on the Giving Pledge and elite philanthropy and considers a number of directions for future research.

\section{Elite Philanthropy}

Over the past three decades, studies of wealthy donors have established various typologies of core motives for philanthropic action (Breeze \& Lloyd, 2013; Schervish \& Havens, 2002; Worth et al. 2019). We build on these typologies, but consider the public letters as primarily constitutive of a public discourse, rather than necessarily reflecting true psychological motives for giving. Akin to Andrew Carnegie's Gospel of Wealth (Carnegie, 1889/ 2017), the letters offer insights into a collective understanding about the proper societal role of elite philanthropists. As Horvath and Powell recently put it: "We view philanthropy not as "mere" acts of generosity by the wealthy, but as reflective signposts that mark collective understandings of democracy, wealth, and the kind of society we have become" (Horvath \& Powell, 2020, 85).

Earlier studies of wealthy donors have pointed to shared social expectations in a "homogenous elite environment" (Ostrower, 1995: 11), and the role of family, business relations, and religion. Various motivating and enabling factors across studies include a desire to give back and make a difference, a belief in the cause, frameworks of consciousness (values and beliefs), psychological rewards, and the capacity to engage in philanthropy (Breeze \& Lloyd, 2013; Osili, 2011, 13; Schervish, 2005, 72). Although many of the identified motives are also found among the less wealthy, what sets wealthy donors truly apart is their belief in a capacity to singlehandedly shape the world to one's own desires. This sense of "hyperagency" means feeling "capable of establishing the institutional framework within which they and others live" (Schervish, 2005, 60). The perceived ability to shape overall conditions for others may create a greater sense of philanthropic efficacy based on exerting control through foundations or similar donative vehicles.

Specific research on billionaire philanthropy and the Giving Pledge has found that self-made billionaires donate more and are more likely to sign the Giving Pledge than 
those with inherited wealth (Hickman et al. 2015). Selfmade billionaires are also more likely to spend money on luxury items, which supports the notion that the manner of wealth acquisition has an impact on subsequent spending (Coupe \& Monteiro, 2016). Sadeh et al. analyzed letters of 96 Giving Pledge signatories and identified ten motives: no other needs, harmful effects of inheritance, personal benefits, impact, legacy, influence by others, wanting to influence others, values, luck, and being blessed (Sadeh et al. 2017). Giving Pledge members from the technology sector have been found to be more optimistic about philanthropy "making the world a better place" than other pledgers (Brockmann et al. 2021, 21).

Building on studies identifying distinct individual giving motives, scholars have proposed the recognition of broader donor profiles defined by various predispositions, including an altruistic attitude (affective or normative), a focus on personal benefits (e.g., social status, tax relief, or avoiding harm to heirs), or a desire to build a legacy (Worth et al. 2019). Such profiles can be understood as important building blocks of a distinct philanthropic discourse among the wealthy as they define their role in society. The tradition of such a discourse goes back to Carnegie's insistence that wealth inequality was a necessary condition of advancing humanity, but also created special obligations for the wealthy, including giving away their fortunes while still alive (Carnegie, 1889/2017). His pronouncements became central to subsequent philanthropic discourses as he defended the capitalist economic system, rejected mere charitable almsgiving, and asked wealthy individuals to use major gifts in supporting formal and informal education, medical research, recreation for the masses, and the arts. The Giving Pledge and its discourse expressed in the letters can then also be understood as an explicit or implicit response to critics of billionaire philanthropy who claim that it aims to undermine popular pressures for income redistribution through taxing the wealthy (Dalzell, 2013, 145).

In sum, research on wealthy donors has established various lists of motives revealing a consistent pattern of common categories (summarized in Table 3). Some of these motives are also prevalent in the general public (e.g., wanting to make a difference), while others are unique to the wealthy (e.g., concerns about wealth harming children). However, prior Giving Pledge research has been limited to interpreting self-described statements on giving as inherent motives rather than as more outward facing rationales constituting a distinct philanthropic discourse. In this study, we show how distinct explanations for giving are part of underlying rationales and a discourse among the wealthy expressed in the Giving Pledge letters. While the idea of psychological motivations enables analyses of individual giving preferences, the emphasis on broader rationales supports an understanding of the collective explanation for generosity among elite philanthropists. The Giving Pledge and its letters constitute a platform and discourse not just designed to recruit other wealthy donors, but to also define publicly what is appropriate philanthropic behavior for the wealthy, as well as to collectively shape public perceptions of wealthy donors (Horvath \& Powell, 2020, 86; Liu \& Baker, 2016).

\section{The Giving Pledge: Background and Demographics}

In 2009, Warren Buffett and Bill and Melinda Gates organized a number of informal meetings of wealthy donors to share their philanthropic experiences. The stated goal was to explore different approaches to increasing philanthropic generosity among billionaires. These private conversations revealed a number of concerns about possible public scrutiny as well as challenges of setting up and maintaining effective philanthropic vehicles. Buffett and Gates settled on creating a voluntary public pledge to give away half of one's wealth before or at death. The founders committed to personally recruiting other pledgers, and Melinda Gates insisted during these discussions that both husbands and wives needed to be included because "even if he's the one who made the money, she's going to be the real gatekeeper" (quoted in: Loomis, 2010).

When the Giving Pledge was announced in 2010, its initial supporters assumed that this type of gentle social pressure would be most effective in starting a movement for greater philanthropic engagement. "The organizers were galvanized by the idea that the excitement and passion evident in the stories told at the initial gathering were contagious, and that if the enthusiasm was shared, the Pledge organizers could convince other wealthy individuals to more actively engage their philanthropic responsibility" (Soskis, 2017, 45). Although the pledged funds are not pooled, an annual retreat has become a major opportunity for shared learning and social recognition (Callahan, 2017, 26). The Giving Pledge expresses the hope that "a group coming forward to be explicit about their intentions" will improve the effectiveness of philanthropy by sharing information about the selection of worthy causes as well as about how to organize philanthropic actions with a focus on effectiveness (The Giving Pledge, 2019).

By March 2020, after a decade of existence, membership in the Giving Pledge stood at 209 signatories. This number represents more than ten percent of the 2,095 billionaires identified by Forbes (Forbes, 2020). All signatories of the Giving Pledge are featured on a dedicated website (givingpledge.org). There are 120 couples, 78 single men, and 11 single women. In 2013, the Giving 
Table 1 Statistical associations between industry, age, and net worth (\$USD billions) at the time of the pledge commitment

\begin{tabular}{llllllll}
\hline & \multicolumn{3}{l}{ Age at pledge } & & \multicolumn{3}{l}{ Net worth at pledge } \\
\cline { 2 - 3 } & Mean & S.d & Freq & & Mean & S.d & Freq \\
\hline Industry & & & & & & \\
Brick and mortar & 68.56 & 12.57 & 99 & & 3.75 & 3.54 & 55 \\
Finance & 64.02 & 12.50 & 59 & & 5.21 & 8.51 & 35 \\
Tech & 53.15 & 14.57 & 48 & & 7.12 & 11.79 & 30 \\
Overall & 63.67 & 14.35 & 206 & & 5.02 & 7.88 & 120 \\
\hline
\end{tabular}

One way analysis of variance for age at pledge: $F=22.59, p=0.00$. One way analysis of variance for net worth at pledge: $F=1.81$, $p=0.17$. Multivariate analysis of variance (Wilks' lambda): $F=7.14$, $p=0.00, n=120$

Pledge was opened to international signatories. After an initial cohort of 57 pledgers joined in 2010, an average of close to 17 new pledgers joined annually between 2011 and 2019. Based on public information available at Forbes.com (Forbes, 2020), we collected basic demographic information about the pledgers. Their average age at the time of joining was 63.67 years. About three-quarters of the pledge population $(157,75.11 \%)$ are US nationals. The next largest group are UK nationals $(12,5.7 \%)$. The remaining 40 pledgers are nationals of 22 other countries. The pledgers control estimated combined assets of well over USD \$1 trillion. Their average wealth is USD $\$ 5.51$ billion (in nominal terms), while the median wealth is USD $\$ 2.40$ billion. Forbes categorized 174 (83\%) of the pledgers as self-made.

Among the 209 pledgers, 101 (48\%) made their wealth in traditional "brick and mortar" industries (e.g., construction, energy/mining, entertainment/news media, manufacturing, real estate, retail), $60(29 \%)$ in finance (e.g., banking and investment), and $48(23 \%)$ in technology services and software. Table 1 reveals that the ages and fortune sizes at which pledgers decided to join the pledge vary by industry. For example, pledgers in the tech industry tended to join younger and with larger fortunes.
Among the 209 individuals and couples committed to the Giving Pledge by March 2020, 187 had submitted a letter along with their pledge. The average length of the letters is 441.58 words (median: 400 words). In order to identify any demographic or other differences between those who submitted a letter and the 22 who did not, we compared both groups (Table 2). We found that letter writers are wealthier and those from traditional "brick and mortar" industries were more likely to submit a letter than those from the technology and finance sectors.

\section{Analytical Procedure}

To understand elite philanthropic discourse as represented in the Giving Pledge letters, we conducted a mixed-method analysis in several steps. In step one, we imported the letters into computer-aided qualitative data analysis software (CAQDAS, specifically NVivo 12), where we added personal data about the pledgers, including their citizenship, their Forbes self-made scores, age, and fortune size at time of the pledge, number of children, gender of the primary wealth generator, and industry.

The second step identified the main categories of information contained within the letters: explanations for giving (identified in 170 letters), philanthropic causes discussed (136), reasons given for joining the Giving Pledge (82), and philanthropic principles guiding giving (49). Other contents included how signatories acquired their wealth, general statements on the Giving Pledge and its founders, and miscellaneous topics, such as descriptions of global challenges.

The third step involved classifying the causes identified in the letters based on the National Taxonomy of Exempt Entities (NTEE) Core Codes (Jones, 2019). More specific subcategories of causes were then added inductively based on the mentioned philanthropic activities. For example, wherever possible we used the subcategories "higher
Table 2 Demographic comparisons by letter availability

\begin{tabular}{|c|c|c|c|c|}
\hline & \multicolumn{2}{|c|}{ Letter } & \multicolumn{2}{|c|}{ No letter } \\
\hline & Freq & Mean & Freq & Mean \\
\hline Net worth at pledge (\$USD billions) & 110 & 5.22 & 10 & 2.83 \\
\hline US citizenship (yes $=1$ ) & 186 & 0.74 & 22 & 0.77 \\
\hline Male gender of wealth creator $($ male $=1$ ) & 186 & 0.93 & 22 & 0.91 \\
\hline Number of children & 186 & 2.78 & 22 & 2.50 \\
\hline Self-made wealth $($ yes $=1$ ) & 187 & 0.83 & 22 & 0.86 \\
\hline \multicolumn{5}{|l|}{ Industry } \\
\hline Brick and mortar & 94 & 50.27 & 7 & 31.82 \\
\hline Finance & 52 & 27.81 & 8 & 36.36 \\
\hline Technology & 41 & 21.93 & 7 & 31.82 \\
\hline
\end{tabular}


education" and "K-12" to further specify references to spending on educational causes.

The fourth step examined the explanations for giving in more detail. While we had established a set of initial codes informed by prior literature on giving motives, we also relied on inductive open coding (Hsieh \& Shannon, 2005) to categorize explanations for giving not found in the literature. One researcher iteratively reviewed the textual content and the emergent coding categories to develop a codebook that combined similar concepts together while differentiating between fundamentally different concepts (Elliott, 2018). For example, terms such as "joy," "happiness," and "satisfaction" associated with current giving were all categorized as an explanation of "personal gratification" distinguished from other explanations. All researchers collaborated in reviewing the existing literature to establish a baseline of possible explanations as well as revising the codebook and establishing the final list of main categories. Table 3 summarizes the coding scheme for giving explanations.

In a fifth step, the data from coding were imported into Latent GOLD 5.1 for latent class analysis (LCA). While prior literature has offered taxonomies of distinct or overlapping motives, we endeavored to identify underlying or latent rationales that could give rise to the observed explanations. LCA is much more informative than simply computing summary statistics for the nine explanations because LCA takes the entire pattern of explanations into account for each letter. Specifically, with nine giving explanations, there are $2^{9}$ or 512 distinct patterns of explanations possible. LCA, as explained in the next section, provides a more concise and powerful understanding of the letters than what is feasible and interpretable with qualitative coding and summary statistics alone.

Finally, in the sixth step, exemplary letters expressing each rationale were chosen for more in-depth analysis and discussion. The presentation of exemplary letter contents was then supplemented with additional biographical information on the chosen pledgers. This information provides context for the philanthropic behavior of the most typical pledgers representing each of the two rationales.

\section{Empirical Findings}

The results are organized into two main sections. The first part provides an overview of the pledgers' preferred philanthropic causes directly identified in the letters. The

Table 3 Explanations for giving

\begin{tabular}{|c|c|c|}
\hline Code $(n=187)$ & Coding description & $\begin{array}{l}\text { References and alternative terminologies in the } \\
\text { literature }\end{array}$ \\
\hline $\begin{array}{l}\text { Impact/making a difference; } \\
\text { mentioned in } 79 \text { letters } \\
(42.20 \%)\end{array}$ & $\begin{array}{l}\text { Use of terms such as "impact," "benefit to others," } \\
\text { "making a difference"; references to solving } \\
\text { societal problems, instrumental use of wealth, or } \\
\text { helping others }\end{array}$ & $\begin{array}{l}\text { Breeze and Lloyd (2013) (belief in cause); Schervish } \\
\text { (2005) (hyperagency, urgency, effectiveness); } \\
\text { Sadeh et al. (2017); Worth et al. (2019) (impact) }\end{array}$ \\
\hline $\begin{array}{l}\text { Gratitude toward others (based } \\
\text { on past experiences), } \\
\text { mentioned in } 70 \text { letters } \\
(37.40 \%)\end{array}$ & $\begin{array}{l}\text { Use of terms such as "gratitude," "giving back," } \\
\text { "being blessed," "being lucky" (personal benefits } \\
\text { received from society in the past prompt wanting to } \\
\text { help others, "pay it forward") }\end{array}$ & $\begin{array}{l}\text { Ostrower (1995) (obligation); Worth et al. (2019) } \\
\text { (reciprocity); Hickman et al. (2015) } \\
\text { (responsibility); Sadeh et al. (luck/good fortune) }\end{array}$ \\
\hline $\begin{array}{l}\text { Personal gratification (resulting } \\
\text { from current giving); } \\
\text { mentioned in } 54 \text { letters } \\
(28.88 \%)\end{array}$ & $\begin{array}{l}\text { Use of terms such as "enjoyment," "satisfaction," } \\
\text { "psychological returns," or "pleasure" (personal } \\
\text { benefits experienced while giving prompt more } \\
\text { giving) }\end{array}$ & $\begin{array}{l}\text { Breeze and Lloyd (self-actualization); Ostrower } \\
\text { (1995) (reward, joy); Sadeh et al. (2017) (warm } \\
\text { glow); Worth et al. (2019) (benefits) }\end{array}$ \\
\hline $\begin{array}{l}\text { Family upbringing; mentioned } \\
\text { in } 47 \text { letters }(25.13 \%)\end{array}$ & $\begin{array}{l}\text { Description of how giving was learned at young age } \\
\text { from parents and other family members }\end{array}$ & $\begin{array}{l}\text { Ostrower (1995); Schervish (2005) (models of } \\
\text { experience from one's youth) }\end{array}$ \\
\hline $\begin{array}{l}\text { Stewardship; mentioned in } 24 \\
\text { letters }(12.83 \%)\end{array}$ & $\begin{array}{l}\text { Statement that wealth is not their own; use of terms } \\
\text { "stewards" or "trustees"; references to abstract } \\
\text { principles of justice or equality }\end{array}$ & Worth et al. (2019) (altruism based on moral values \\
\hline $\begin{array}{l}\text { Inheritance causing harm to } \\
\text { offspring; mentioned in } 20 \\
\text { letters }(10.16 \%)\end{array}$ & $\begin{array}{l}\text { Statement on how a large inheritance can harm } \\
\text { offspring }\end{array}$ & $\begin{array}{l}\text { Sadeh et al. (2017); Worth et al. (2019) (limit } \\
\text { inheritance to heirs) }\end{array}$ \\
\hline $\begin{array}{l}\text { Excess wealth; mentioned in } 19 \\
\text { letters }(11.11 \%)\end{array}$ & $\begin{array}{l}\text { Reference to having more wealth than personally } \\
\text { needed and/or possible to spend in a lifetime }\end{array}$ & $\begin{array}{l}\text { Breeze and Lloyd (2013) (surplus money); Sadeh } \\
\text { et al. (2017) (no other need); Ostrower (1995); } \\
\text { Schervish (2005) (discretionary resources) }\end{array}$ \\
\hline $\begin{array}{l}\text { Legacy; mentioned in } 15 \text { letters } \\
\quad(8.02 \%)\end{array}$ & Term "legacy" used & Worth et al. (2019) (Tradition/legacy/memorial) \\
\hline $\begin{array}{l}\text { Religion/spirituality; mentioned } \\
\text { in } 14 \text { letters }(7.49 \%)\end{array}$ & Reference to religious or spiritual texts or inspiration & $\begin{array}{l}\text { Ostrower (1995); Schervish (2005); Worth et al. } \\
\text { (2019) (obligation of religious faith) }\end{array}$ \\
\hline
\end{tabular}


second part illustrates the nine explanations for giving found in the letters and then uses LCA to identify and examine underlying discursive rationales for giving.

\section{Philanthropic Causes Identified}

One hundred and thirty-six (73.8\%) of the 187 letters contain references identifying specific philanthropic causes supported by the signatories. Table 4 summarizes the nine major causes and their subcategories. Many pledgers mentioned more than one cause or cause subcategory in their letters. Education and health are by far the leading categories and also dominate as subcategories the category of international causes as the third most frequently mentioned philanthropic investment. The letters do not provide a complete picture of pledgers' philanthropic activities, but the pattern of preferred philanthropic investments closely aligns with Andrew Carnegie's top recommendations of philanthropic investments (Carnegie, 1889/2017), and also mirrors the current strategic foci of the Bill and Melinda Gates Foundation. Although investments in health and education can certainly be transformational, it is surprising to see these similarities considering the vast expansion of government programs in these areas during the twentieth century.

\section{Giving Explanations}

One hundred and seventy of the 187 letters (90.9\%) expressed at least one of the nine main explanations for giving identified in the letters. Four leading explanations were mentioned in at least one quarter of the letters: impact/making a difference (79 letters), gratitude toward others (70), personal gratification (54), and family upbringing (47). The remaining explanations include an invocation of principles of stewardship often based on principles of justice (24), a concern that a large inheritance will harm offspring (20), excess wealth with no better use (19), leaving a legacy (15), and religion/spirituality (14). Table 3 includes descriptive statistics for the nine explanations.

\section{Giving Rationales}

Individual letters typically contain more than a single explanation, and similar combinations of explanations commonly appear across multiple letters. These patterns imply the presence of underlying subgroups of pledgers, with each subgroup exhibiting a distinct rationale for giving. There are many techniques available for identifying subgroups and classifying observations. These include distance-based techniques such as k-means and hierarchical cluster analysis and model-based techniques such as latent class analysis. Because it is model-based, LCA offers important advantages over traditional cluster analysis techniques. Notably, LCA enables more rigorous procedures for model selection and for identifying exemplary observations, as described below.

In the context of LCA, the pattern of explanations observed in any particular letter is assumed to depend upon the pledger's unobserved subgroup or rationale. Essentially, LCA posits a latent variable that explains the observed data patterns. In statistical terms, the nine explanations are statistically independent conditional on the latent variable - a condition called local independence. Although LCA is a model-based tool in which classification occurs after model estimation, it effectually performs a function similar to traditional cluster analysis techniques. In traditional cluster analysis, cases are organized into clusters using distance measures such that cases within a

Table 4 Causes identified in the giving pledge letters

\begin{tabular}{llll}
\hline Cause & Freq & $\%$ & Subcategories \\
\hline Education & 82 & 43.85 & K-12 (45), higher education (28), general education (20) \\
Health & 59 & 31.55 & Medical research (35), Health services (30), general health (4) \\
International & 46 & 24.60 & Development (38), peace and conflict resolution (9), humanitarian relief (6) \\
Environment, animal & 33 & 17.65 & Conservation (25), climate (12), animal welfare/general environment (2 each) \\
$\quad$ welfare & & & \\
Public or social benefit & 30 & 16.04 & Non-medical research (16), community development (12), human and civil rights (4) \\
Human services & 25 & 13.37 & Women (8), children (6), military (4) homeless/food security/economic opportunity (3 each) \\
Arts, culture, humanities & 24 & 12.83 & Not applicable \\
Public policy & 20 & 10.70 & General public policy (8), governance (5), healthcare reform (3), crime/drug/media policy (2 each) \\
Religion & 10 & 5.35 & Not applicable \\
\hline
\end{tabular}

Subcategory totals may exceed the frequency counts because some pledgers mentioned more than one subcategory. Causes were mentioned in 136 of 187 letters; percentages are calculated based on $n=187$ 
cluster are very similar and cases in different clusters are very different. As LCA is often used to classify observations into clusters (and is sometimes referred to as latent class cluster analysis), the subgroups identified through LCA are typically called clusters. The probabilities of observing a given explanation in a letter conditional on its cluster membership constitute a cluster's profile. In the present application, clusters represent distinct subgroups of pledgers and cluster profiles represent distinct rationales for giving. Several latent class models were estimated.

One of the many advantages of LCA over traditional cluster analysis techniques is that it affords more rigorous criteria for model selection. Table 5 displays fit statistics for six latent class models with 1-5 clusters. Model selection begins with an assessment of Models 1-5. The Bayesian information criterion (BIC) monotonically increases with the number of clusters and so does not initially provide decisive guidance for model selection. However, the Akaike information criterion (AIC) indicates that Model 2 is the preferred model. (It has the lowest value.) Additionally, bootstrap log-likelihood difference tests were performed to determine whether model fit significantly improves with each increase in the number of clusters. This procedure reveals that incrementing from one to two clusters provides the only statistically significant improvement in model fit. Thus, a two-cluster model is warranted, and no further incrementing is justified. One major assumption of LCA is so-called local independence, or the condition that the indicator variables (the nine giving explanations) are statistically independent within each category of the posited latent variable. This assumption can be assessed by examining a model's bivariate residuals (Appendix). Model 2 exhibits a local dependence between personal gratification and gratitude toward others. This residual association unexplained by the latent variable is likely due to the inherent conceptual overlap between the concepts of gratification and gratitude. To accommodate this overlap, Model 6 introduces a direct effect between the two indicator variables, essentially relaxing the local independence assumption (Hagenaars, 1988; Vermunt \& Magidson, 2002). Model 6 exhibits local independence (Appendix) and is unambiguously preferred according to the AIC. Model 6 also represents a statistically significant improvement in model fit relative to Model 2, indicating that the inclusion of the direct effect is justified. Model 6 also has lower classification error compared to Model 2. Model 6 is the preferred model.

Table 6 displays the cluster profiles for Model 6. About $87 \%$ of pledgers belong to Cluster 1 . Pledgers in this cluster mainly emphasized gratitude toward others (43\%) and impact/making a difference (41\%), and to lesser degrees, family upbringing (28\%) and personal gratification $(25 \%)$. The remaining $13 \%$ of pledgers belong to Cluster 2. These pledgers mentioned inheritance causing harm to offspring (71\%), personal gratification (54\%), impact/making a difference (48\%), and excess wealth (39\%). Comparing the two profiles, pledgers in Cluster 2 are much more likely to mention inheritance causing harm to offspring $(+72 \%)$, excess wealth $(+33 \%)$, and personal gratification $(+28 \%)$, whereas pledgers in Cluster 1 are much more likely to mention gratitude toward others $(+41 \%)$ and family upbringing $(+25 \%)$.

Cluster 1 reveals a social-normative rationale, describing giving primarily in reference to a sense of responsibility and obligation. One dutifully gives back because society has enabled one's success in the past (reciprocity) or one was taught to give by family (socialization). The rationale expressed in Cluster 2 emphasizes more the consequences of (not) giving. Harm to children, psychological benefits, or excess wealth are all references to a sense of what are the best uses of wealth, rather than the fulfillment of an expected social obligation.

The two profiles do not pitch a purely altruistic rationale against a purely self-interested one. Altruistic language pervades most of the letters, and this is especially visible in the prevalence of "making a difference" as a popular

Table 5 Model selection

\begin{tabular}{|c|c|c|c|c|c|c|c|c|}
\hline Model & Clusters & LL & $\mathrm{BIC}(\mathrm{LL})$ & $\mathrm{AIC}(\mathrm{LL})$ & Class. Err & Reference model & -2LL Diff & $p$ value \\
\hline Model 1 & 1 & -767.52 & 1582.12 & 1553.04 & & & & \\
\hline Model 2 & 2 & -748.58 & 1596.56 & 1535.16 & 0.06 & Model 1 & 41.29 & 0.00 \\
\hline Model 3 & 3 & -739.61 & 1630.93 & 1537.23 & 0.14 & Model 2 & 21.88 & 0.08 \\
\hline Model 4 & 4 & -732.64 & 1669.30 & 1543.28 & 0.14 & Model 3 & 19.89 & 0.11 \\
\hline Model 5 & 5 & -728.52 & 1713.36 & 1555.04 & 0.13 & Model 4 & 10.17 & 0.58 \\
\hline Model 6 & 2 & -745.49 & 1595.60 & 1530.98 & 0.04 & Model 2 & 6.18 & 0.01 \\
\hline
\end{tabular}

$n=187 . \mathrm{LL}=\log$-likelihood. BIC $=$ Bayesian information criterion. AIC $=$ Akaike information criterion. $p$ values are provided for the corresponding bootstrap - 2LL difference tests between Model and Reference model. Statistically significant values $(p<0.05)$ indicate that Model provides improved fit relative to the Reference model. The second row indicates that a 2-cluster model is preferred to a one-cluster model. The sixth row indicates that the 2-cluster model with the direct effect is preferred to the two-cluster model without the direct effect 
Table 6 Cluster profiles

\begin{tabular}{lll}
\hline & Cluster 1 & Cluster 2 \\
\hline Cluster Size & 0.87 & 0.13 \\
Giving explanation & & \\
Inheritance harming offspring & 0.02 & 0.74 \\
Excess wealth & 0.06 & 0.39 \\
Family upbringing & 0.28 & 0.03 \\
Gratitude toward others & 0.43 & 0.01 \\
Impact/making a difference & 0.41 & 0.48 \\
Legacy & 0.08 & 0.10 \\
Personal gratification & 0.25 & 0.54 \\
Religion/spirituality & 0.08 & 0.07 \\
Stewardship & 0.14 & 0.06 \\
\hline
\end{tabular}

$n=187$. The values in the first row represent the estimated proportion of letters belonging in Cluster 1 and in Cluster 2, respectively. The other values represent the probabilities of observing the corresponding giving explanation conditional on the corresponding cluster. For example, about 87 percent of letters are classified into Cluster 1 . About two percent of those letters mentioned inheritance harming offspring, six percent mentioned excess wealth, and so on. About 13 percent of letters are classified into Cluster 2. About 74 percent those letters mentioned inheritance harming offspring, about 39 percent mentioned excess wealth, and so forth. The profiles are initially interpreted by comparing and contrasting the conditional probabilities between the two clusters

explanation for giving across both profiles. What distinguishes references to "making a difference" in the two profiles is the overall context. Signatories in the majority group tend to mention impact as an expression of an internalized sense of obligation, whereas signatories in the minority group link impact to specific personal or family outcomes.

\section{Giving Rationales: Qualitative Profiles of Representative Pledgers}

To further interpret the complex nature of pledgers' philanthropic rationales, this section examines selected passages from letters that exemplify each rationale. Exemplarity is measured by the degree to which each pledger's letter belongs to the cluster to which it was assigned, or in statistical terms, each letter's posterior membership probability (PMP) for the modal assignment. PMPs range from zero, indicating not at all exemplary, to one, indicating exemplary. Letters were ranked within each cluster by PMP, and the top-ranking letters were selected for further interpretation and elaboration.
Expressing a Sense of Obligation and Duty: The Social-Normative Rationale

The majority of signatories found it most appropriate to explain their giving with reference to a sense of obligation formed early in childhood or emerging from their wealth. Azim Premji's 2013 letter (PMP $=1.00)$ emphasizes personal history as well as a duty to serve society:

My mother was the most significant influence in my life as I was growing up. She was a strong woman, and a deeply committed person. Though she was a Medical Doctor, she did not actually practice medicine, but dedicated a large part of her life, close to 50 years, in helping to build and run a charitable hospital for Polio and Cerebral Palsy Children in Bombay. [...] In those days, a newly independent India was abuzz with a sense of idealism and a genuine sense of nation building; this influenced me as well. I was deeply influenced by Gandhi's notion of holding one's wealth in trusteeship, to be used for the betterment of society and not as if one owned it. [...] I strongly believe that those of us, who are privileged to have wealth, should contribute significantly to try and create a better world for the millions who are far less privileged.

Premji, who turned his father's cooking oil business into India's largest software company Wipro, has to date transferred about $\$ 21$ billion to his family foundation. Using computer technology, Premji has invested in improving elementary education in rural areas of India. In 2017, he was awarded the Carnegie Medal of Philanthropy. The award citation emphasizes his "conscience, integrity, and compassion that have guided his visionary giving" (Carnegie Medal of Philanthropy, 2017).

Jorge and Darlene Pérez's 2012 letter $(P M P=1.00)$ also emphasizes gratitude as well as an urgent need to address economic inequality. It also refers to giving as the "right thing to do."

I came to this country in 1968 without a penny to my name but with the hope of becoming successful and leaving some type of meaningful legacy behind. I was fortunate to have received scholarships that enabled me to get undergraduate and graduate degrees. Also, I was lucky to develop my own company into a successful real estate development entity. While I worked hard to get where I am, it would have never happened without the assistance of many individuals and institutions along the way.

I am truly one of the lucky ones. But most people, both in the United States and around the world, do not get the opportunities that were presented to me. 
Unfortunately, because of lack of resources and a misdistribution of wealth, we have seen the gap between the rich and the poor grow wider. [...] It is obvious to me that government cannot solve all our problems. Whether it is in education, health or the arts, the needs are immense and growing. It is because of this that it is so very important for us, the lucky few, to contribute our resources to make this a better and more fair world.

As I told you, I spent a good part of this summer discussing with my family the importance of making the Giving Pledge. We all agreed that it is just THE RIGHT THING TO DO. So, count us in.

Jorge Pérez became a real estate developer and chairman of the Related Group after having worked for the Miami city government. His background as a public servant may partly explain the letter's social-normative rationale for giving.

The co-founders of the Giving Pledge, Bill, and Melinda Gates $(\mathrm{PMP}=1.00)$ also express a predominantly socialnormative rationale in their letters submitted in 2010. The Gates letter elaborates on how the idea of giving back emerged in childhood and from the responsibility tied to possessing great wealth.

We have been blessed with good fortune beyond our wildest expectations, and we are profoundly grateful. But just as these gifts are great, so we feel a great responsibility to use them well. [...]

Both of us were fortunate to grow up with parents who taught us some tremendously important values. Work hard. Show respect. Have a sense of humor. And if life happens to bless you with talent or treasure, you have a responsibility to use those gifts as well and as wisely as you possibly can.

A majority of signatories highlight the social and obligatory nature of giving. They explain how their relations with family and society at large have prompted them to give back. They also express a belief that acquired wealth creates responsibilities to bring one's talents to the world of philanthropy. The needs of society and a desire to have profound impact play important roles in their written accounts.

\section{Expressing a Sense of "best use": The Personal- Consequentialist Rationale}

In contrast to the emphasis on obligation and responsibility, a smaller set of letters coalesces around explanations focused on the perceived best uses of wealth. Herb and Marion Sandler's 2010 letter $(\mathrm{PMP}=0.99)$ highlights avoiding the harm of leaving an excessive inheritance, the superior use of resources for philanthropy rather than consumption, and psychological benefits experienced personally.

When you think about it, no other approach seems to make sense. Passing down fortunes from generation to generation can do irreparable harm. In addition, there is no way to spend a fortune. How many residences, automobiles, airplanes and other luxury items can one acquire and use? [...]

These are a few examples of the sense of fulfillment we experienced in "giving back" and which, among other things, led to our decision to devote our energy and money to making a difference in people's lives. Believe it or not, the psychic income-the highs if you will-associated with giving money away thoughtfully and effectively has been even more gratifying than running a successful business.

Through their bank, Golden West, Herb and Marion Sandler were known for "making loans to communities that had been subject to racially and economically restrictive redlining practices" (Meeker, 2019). They became major donors of progressive causes, including being involved in the creation of The Center for American Progress, a policy think tank, and ProPublica, a nonprofit engaged in investigative journalism. The letter provides a distinct personal-consequentialist account emphasizing specific benefits of giving, rather than social and normative responsibilities. The statement on wanting to make a difference is followed by a reference to personal gratification, rather than references to social obligation. Although it is certainly possible that the Sandlers may have also been influenced by a sense of social obligation, their pledge letter discusses the more direct consequences of giving for themselves and their heirs.

Tom and Marion Hunter's 2015 letter $(\mathrm{PMP}=0.99)$ also highlights the burden of a large inheritance alongside the personal enjoyment of giving. It also emphasizes that their excess wealth had no better use than philanthropy.

"Marion and I came to the conclusion we would not burden our 3 kids with great wealth. We would encourage them to find their passion and support them. We then decided that as a family we didn't need any more personal wealth. I also decided that I want to keep making money through our Private Equity West Coast Capital but the profits would flow to The Hunter Foundation. We don't want to be the richest guys in the graveyard we want to "do good" while we are still alive. Why let others have all the fun? For those who are thinking about this. All I would say is seeing a project we have helped, work is a bigger sense of achievement than any business deal I have ever done." 
Hunter built one of Europe's largest independent sports retailer before moving into private equity. The Hunter Foundation was founded in 1998 and became a major investor in philanthropic causes in Scotland as well as subSaharan Africa. During the 2000s, Hunter collaborated with the Clinton Foundation and focused on leveraging his own donations to attract other funders for increased collective impact. In 2013, Tom Hunter received the Carnegie Medal of Philanthropy (Carnegie Medal of Philanthropy, 2013).

Ted and Vada Stanley's 2012 letter $(\mathrm{PMP}=1.00)$ is adamant about the idea of making a difference and the various benefits emerging from having dedicated much of their wealth to philanthropy.

It has been surprising to us to see how much difference our money has made-considering that our funds are dwarfed by the huge sums spent by government in this same area. [...]

What could be more useless than accumulating huge piles of money you will never spend? (and leaving too much for your children is as likely to harm as to help them.) Much better is to experience the satisfaction of seeing your money make an important difference in some area that could really use your help.

The Stanleys spent most of their wealth on medical research after their son was diagnosed with bipolar disorder. Much of this money went to the Broad Institute, a Cambridge, Massachusetts-based research center founded by fellow pledgers Eli and Edythe Broad. "Best use" is the key argument for giving expressed in the letter, while the notion of altruism is also visible in the professed concern for others in need of help.

This distinct subset of letters emphasizes a personalconsequentialist rationale for giving. This choice of explanations reveals an emphasis on the effects of (not) giving on oneself and the immediate family. Considering the rhetorical commitment to generosity among all signatories, the distinct presence of this rationale does not deny altruistic motives; it simply establishes that a minority of pledgers chose to frame their giving as a benefit to themselves and their families.

\section{Conclusions and Implications}

This mixed-method content analysis of 187 Giving Pledge letters reveals two distinct discursive rationales encoded in billionaires' public explanations for their giving. A dominant social-normative rationale links making a difference to a sense of obligation based on gratitude to society and family upbringing. These letters primarily express what is expected from the wealthy as they consider the appropriate ways of giving back to society. A second, much less prevalent, personal-consequentialist rationale also highlights the idea of making a difference, but focuses on the best use of wealth when considering personal consequences. The rationale highlights the desire to avoid harms caused by an excessive inheritance, the personal benefits experienced in the process of giving, and the lack of any better use for excess wealth.

Beyond the explanations and rationales, the letters portray a nuanced and evolving discourse of elite philanthropy (Horvath \& Powell, 2020). In one sense, the Giving Pledge continues the tradition dating back to Carnegie's Gospel of Wealth, which implored the wealthy to invest their fortunes during their lifetimes. According to Carnegie and many pledgers today, a legitimate response to rising economic inequality is for the wealthy to use their "superior wisdom, experience, and ability to administer" (Carnegie, 1889/ 2017) to improve the lives of everyone through major philanthropic investments in health and education. Surplus wealth should not be left to decedents or the state, rather those with extraordinary business success should apply their acumen to the philanthropic sector. The overall dominance of a social-normative rationale across the letters projects a discursive portrait of benevolent gratitude, which could be interpreted as a defense of excess wealth. Expressed desires to "make a difference" and "give back to society" contribute to a narrative in which billionaires are an exceptionally productive and grateful subset of society. The parallels between Carnegie's vision of wealthy philanthropy expressed in the late nineteenth century and the dominant perspectives of the Giving Pledge letters suggest a limited willingness among today's billionaires to question the root causes of inequality or engage more directly with contemporary critics of this type of philanthropy.

There are a number of possible future research directions. One could pay greater attention to explanations not or rarely mentioned in the letters. A more complete understanding of this discourse would push beyond this analysis to identify what remains unsaid in this discourse. For example, only one signatory (Kaiser) articulated a sense of guilt as a factor, while contemporary critiques of wealth inequality are not openly acknowledged in the letters. Another research agenda could focus more attention on the reasons for the existence of two distinct rationales. One could ask if the dominant social-normative rationale is mainly targeting the general public in order to promote a favorable view of elite philanthropy. The less prevalent personal-consequentialist rationale may then be more targeted at peers to elaborate why giving is in their best interest. Another research agenda could focus on the effectiveness of the Giving Pledge by comparing the actual 
giving behavior of pledgers and non-pledgers. Previous studies have compared pledgers and non-pledgers primarily to explain differences in generosity and the significance of being self-made for philanthropic behavior (Coupe \& Monteiro, 2016). Additional comparisons could also examine the contents of early letters with more recent ones, or explore the role of gender or national or cultural context as possible factors shaping differences across pledgers.

To further evaluate the usefulness of the two rationales identified here, additional writings and speeches of pledgers could be analyzed using automated content analysis (Brockmann et al. 2021). Billionaires may be much less likely to respond to traditional survey or interview requests, which suggests discourse analysis as a means to reconstruct their philanthropic actions by using publicly available data.
Additional data and other methods may also facilitate stronger inferences about underlying psychological motives. Such research tracking the rationales and discourse of billionaire philanthropy will contribute to comparing the philanthropic views of the super-wealthy to those of other societal groups as well as understanding better any differences in philanthropic behavior among billionaires based on age, source of wealth (e.g., industry), or gender.

\section{Appendix}

See Table 7.

Table 7 Bivariate residuals

\begin{tabular}{|c|c|c|c|c|c|c|c|c|c|}
\hline & Inheritance & Excess & Family & Gratitude & Impact & Legacy & Personal & Religion & Stewardship \\
\hline \multicolumn{10}{|l|}{ Model 2} \\
\hline Inheritance harming offspring & - & & & & & & & & \\
\hline Excess wealth & 0.09 & - & & & & & & & \\
\hline Family upbringing & 0.21 & 0.00 & - & & & & & & \\
\hline Gratitude toward others & 0.06 & 0.30 & 1.91 & - & & & & & \\
\hline Impact/making a difference & 0.02 & 1.53 & 0.74 & 0.00 & - & & & & \\
\hline Legacy & 0.01 & 1.34 & 0.69 & 0.10 & 1.65 & - & & & \\
\hline Personal gratification & 0.06 & 0.01 & 0.76 & 4.17 & 2.93 & 2.21 & - & & \\
\hline Religion/spirituality & 0.38 & 0.23 & 0.14 & 3.15 & 1.18 & 0.02 & 0.01 & - & \\
\hline Stewardship & 0.42 & 0.91 & 0.05 & 0.91 & 0.20 & 0.01 & 0.02 & 0.41 & - \\
\hline \multicolumn{10}{|l|}{ Model 6} \\
\hline Inheritance harming offspring & - & & & & & & & & \\
\hline Excess wealth & 0.00 & - & & & & & & & \\
\hline Family upbringing & 0.41 & 0.00 & - & & & & & & \\
\hline Gratitude toward others & 0.09 & 0.14 & 1.61 & - & & & & & \\
\hline Impact/making a difference & 0.04 & 1.53 & 0.74 & 0.00 & - & & & & \\
\hline Legacy & 0.00 & 1.27 & 0.71 & 0.11 & 1.65 & - & & & \\
\hline Personal gratification & 0.00 & 0.09 & 0.51 & 0.00 & 2.85 & 2.22 & - & & \\
\hline Religion/spirituality & 0.17 & 0.14 & 0.09 & 3.50 & 1.15 & 0.02 & 0.00 & - & \\
\hline Stewardship & 0.34 & 0.77 & 0.08 & 1.08 & 0.21 & 0.01 & 0.05 & 0.44 & - \\
\hline
\end{tabular}

Bivariate residuals greater than 3.85 indicate a local dependence at the 0.05 level 
Acknowledgments For valuable feedback, we would like to thank the anonymous reviewers, Sara Konrath, Megan Pontes, Amy Schmitz, and Charles Sellen as well as the discussants and audience members at the 2019 ARNOVA conference in San Diego.

\section{Compliance with Ethical Standards}

Conflict of interest The authors declare that they have no conflict of interest.

Open Access This article is licensed under a Creative Commons Attribution 4.0 International License, which permits use, sharing, adaptation, distribution and reproduction in any medium or format, as long as you give appropriate credit to the original author(s) and the source, provide a link to the Creative Commons licence, and indicate if changes were made. The images or other third party material in this article are included in the article's Creative Commons licence, unless indicated otherwise in a credit line to the material. If material is not included in the article's Creative Commons licence and your intended use is not permitted by statutory regulation or exceeds the permitted use, you will need to obtain permission directly from the copyright holder. To view a copy of this licence, visit http://creativecommons. org/licenses/by/4.0/.

\section{References}

Breeze, B., \& Lloyd, T. (2013). Richer lives: why rich people give. Directory of Social Change.

Brockmann, H., Drews, W., \& Torpey, J. (2021). A class for itself? On the worldviews of the new tech elite. PLOS ONE, 16(1), $\mathrm{e} 0244071$.

Callahan, D. (2017). The givers: Wealth, power, and philanthropy in a new gilded age. Alfred A. Knopf.

Carnegie, A. (1889/2017). The Gospel of Wealth. Carnegie Corporation of New York.

Carnegie Medal of Philanthropy. (2013, October 18). Tom Hunter. Retrieved from https://www.medalofphilanthropy.org/sir-tom-hunter/

Carnegie Medal of Philanthropy. (2017, October 3). Azim Premji. Retrieved from https://www.medalofphilanthropy.org/premjiazim/

Collins, C., \& Flannery, H. (2020). Gilded Giving 2020: How wealth inequality distorts philanthropy and imperils democracy. Institute for Policy Studies.

Coupe, T., \& Monteiro, C. (2016). The charity of the extremely wealthy. Economic Inquiry, 54(2), 751-761.

Dalzell, R. F. (2013). The good rich and what they cost us: The curious history of wealth, inequality, and American Democracy. Yale University Press.

Elliott, V. F. (2018). Thinking about the coding process in qualitative data analysis. Qualitative Report, 23(11), 2850-2861.

Forbes. (2020, March 18). World's billionaires list. https://www. forbes.com/billionaires/

Giving USA Foundation. (2020). Giving USA 2020: The annual report on philanthropy for the year 2019. IUPUI Lilly Family School of Philanthropy.

Hagenaars, J. A. (1988). Latent structure models with direct effects between indicators: Local dependence models. Sociological Methods \& Research, 16(3), 379-405.

Herzog, P. S., \& Price, H. E. (2016). American generosity: who gives and why. Oxford University Press.

Hickman, K., Shrader, M., Xu, D., \& Lawson, D. (2015). The Forbes 400 and the Gates-Buffett giving pledge. ACRN Journal of Finance and Risk Perspectives, 4(1), 82-101.
Horvath, A., \& Powell, W. W. (2020). Seeing like a philanthropist. From the business of benevolence to the benevolence of business. In W. W. Powell \& P. Bromley (Eds.), The nonprofit sector. A research handbook (3rd ed., pp. 81-122). Stanford University Press.

Hsieh, H.-F., \& Shannon, S. E. (2005). Three approaches to qualitative content analysis. Qualitative Health Research, 15(9), 1277-1288.

Jones, D. (2019). National taxonomy of exempt entities (NTEE) codes. Retrieved from https://nccs.urban.org/project/national-taxon omy-exempt-entities-ntee-codes.

Liu, H., \& Baker, C. (2016). Ordinary aristocrats: the discursive construction of philanthropists as ethical leaders. Journal of Business Ethics, 133(2), 261-277.

Loomis, C. J. (2010, June 16). The $\$ 600$ billion challenge. Fortune. Retrieved from https://fortune.com/2010/06/16/the-600-billionchallenge/

McGoey, L. (2016). No such thing as a free gift: The Gates foundation and the price of philanthropy. Verso.

Meeker, M. (2019, April 23). New project release: Marion and Herb Sandler oral history project. Retrieved from https://update.lib. berkeley.edu/2019/04/23/sandler-project/

Osili, U. (2011). Review of literature on giving and high net worth individuals. Retrieved from https://scholarworks.iupui.edu/bit stream/handle/1805/11028/review-of-literature-on-giving-andhigh-net-worth-individuals-october-2011.pdf?sequence $=1$

Ostrower, F. (1995). Why the wealthy give. The culture of elite philanthropy. Princeton University Press.

Reich, R. (2018). Just giving. Why philanthropy is failing democracy and how it can do better. Princeton University Press.

Rooney, P. (2018, September 13). The growth in total household giving is camouflaging a decline in giving by small and medium donors: What can we do about it? Nonprofit Quarterly. Retrieved from https://nonprofitquarterly.org/total-household-growthdecline-small-medium-donors/

Sadeh, J., Tonin, M., \& Vlassopoulos, M. (2017). Why give away your wealth? An analysis of the billionaires' view. In J. Costa-Font \& M. Macis (Eds.), Social Economics (pp. 61-78). MIT Press.

Saunders-Hastings, E. (2018). Plutocratic philanthropy. The Journal of Politics, 80(1), 149-161.

Schervish, P. G. (2005). Major donors, major motives: The people and purpose behind major gifts. New Directions for Philanthropic Fundraising, 47, 59-87.

Schervish, P. G. (2007). Why the wealthy give. In A. Sargeant \& W. Wymer (Eds.), The Routledge companion to nonprofit marketing (pp. 165-180). Routledge.

Schervish, P. G., \& Havens, J. J. (2002). The new physics of philanthropy: The spiritual side of the supply side, Part II. The CASE International Journal of Educational Advancement, 2(3), 221-241.

Skocpol, T. (2016). Why political scientists should study organized philanthropy. PS: Political Science \& Politics, 49(3), 433-436.

Soskis, B. (2017). The history of the giving while living ethic. Atlantic Philanthropies.

The Giving Pledge. (2019). History of the pledge. Retrieved from https://givingpledge.org/About.aspx

Vermunt, J. K., \& Magidson, J. (2002). Latent class cluster analysis. In J. A. Hagenaars \& A. L. McCutcheon (Eds.), Applied latent class analysis (pp. 89-106). Cambridge University Press.

Worth, M. J., Pandey, S., Pandey, S. K., \& Qadummi, S. (2019). Understanding motivations of mega-gift donors to higher education: A qualitative study. Public Administration Review, 80(2), 281-293.

Publisher's Note Springer Nature remains neutral with regard to jurisdictional claims in published maps and institutional affiliations. 